\title{
Monitoring Arus Dan Tegangan Pembangkit Listrik Tenaga Surya Menggunakan Internet Of Things
}

\author{
Aldiansyah $^{1}$, Yosi Apriani" ${ }^{* 2}$, Zulkiffli Saleh ${ }^{3}$ \\ ${ }^{1,2,3}$ Program Studi Teknik Elektro Fakultas Teknik Universitas Muhammadiyah Palembang \\ email: ${ }^{1}$ aldiansyah774419@gmail.com, ${ }^{* 2}$ yosi_apriani@um-palembang.ac.id, \\ ${ }^{3}$ zulkifflisaleh64@gmail.com
}

\begin{abstract}
Abstrak
Penerapan teknologi Pembangkit Listrik Tenaga Surya (PLTS) untuk memanfaatkan potensi energi surya yang tersedia merupakan solusi yang tepat dalam mengurangi ketergantungan terhadap penyedia energi PLN. Tetapi beberapa PLTS belum dilengkapi dengan alat monitoring arus dan tegangan.Termasuk pada PLTS di klinik LKC Dompet Duaffa Palembang tidak dilengkapi dengan alat monitoring arus dan tegangan. Dimana pada saat bekerja inverter maka baterai seharusnya terlepas dari inverter hal ini ditujukan untuk menghindari baterai terjadi over discharge karena daya keluaran pada inverter saat on grid akan bekerja maksimum. Oleh karena itu mengembangkan sistem monitoring arus dan tegangan secara Internet of Things (IoT) sehingga bisa dimonitor dari jarak yang jauh dan akan mengatur mekanisme charging dan discharging baterai pada konfigurasi PLTS, sehingga kontinuitas operasi inverter dapat tetap dijaga dalam mensuplai beban.
\end{abstract}

Kata kunci-Monitoring, PLTS, Internet of Things (IoT).

\begin{abstract}
The application of Solar Power Plant (PLTS) technology to utilize the available solar energy potential is the right solution in reducing dependence on PLN energy providers. However, some PLTS are not equipped with current and voltage monitoring tools, including the PLTS at the LKC Dompet Duaffa clinic in Palembang which is not equipped with current and voltage monitoring tools. When the inverter works, the battery should be separated from the inverter, this is intended to prevent the battery from over-discharge because the output power of the inverter when on grid will work at its maximum Therefore, developing a current and voltage monitoring system using the Internet of Things (IoT) so that it can be monitored remotely and will regulate the charging and discharging mechanism of the battery in the PLTS configuration, so that the continuity of inverter operation can be maintained in supplying loads..
\end{abstract}

Keywords - Monitoring, PLTS, Internet of Things (IoT).

\section{PENDAHULUAN}

Dompet Duaffa Republika adalah lembaga nirlaba milik masyarakat Indonesia yang berhidmat mengangkat harkat sosial kemanusiaan kaum dhuafa dengan dana ZISWAF (Zakat, Infaq, Sadaqah, dan Wakaf). Dompet Dhuafa akan terus mewujudkan masyarakat berdaya yang bertumpu pada sumber daya lokal melalui sistem yang berkeadilan. Dompet Duaffa Sumatera Selatan mempunyai banyak program yang berfungsi mengangkat derajat para kaum dhuafa. Diantaranya dengan program Layanan Kesehatan Cuma-Cuma (LKC).[1]

Klinik LKC Dompet Duaffa (LKC DD) Palembang sudah tersedia perangkat penghemat daya berupa inverter Pembangkit Listrik Tenaga Surya. Untuk membantu LKC DD Sumsel 
menggunakan peralatan Kesehatan yang menggunakan listrik, diantaranya mesin USG (Ultrasonography), Dental Machine, mesin laser khitan, dan beberapa peralatan kesehatan yang lain. Akan tetapi untuk pengecekan apakah baterai sudah terisi penuh atau belum masih dicek manual sehingga memakan waktu dan tenaga yang cukup besar. [2]

Permasalahannya pada PLTS Klinik LKC Dompet Duaffa Palembang tidak dilengkapi dengan alat monitoring arus dan tegangan. Dimana pada saat bekerja inverter maka baterai seharusnya terlepas dari inverter hal ini ditujukan untuk menghindari baterai terjadi over discharge karena daya keluaran pada inverter saat on grid akan bekerja maksimum. Sementara pada saat off grid baterai harus terhubung dengan inverter untuk menstabilkan daya keluaran inverter karena adanya fluktuasi sumber dan beban AC. [3]

Penelitian ini bertujuan untuk mengembangkan sistem monitoring arus dan tegangan secara IOT sehingga bisa dimonitor dari jarak yang jauh dan akan memonitor kenerja PLTS secara optimal dan bisa mendeteksi gangguan secepat mungkin pada PLTS, sehingga kontinuitas operasi inverter dapat tetap dijaga dalam mensuplai beban.[4], [5]. Penelitian ini merancang dan membuat sebuah alat yang merupakan suatu sistem monitoring arus dan tegangan menggunakan internet of things (iot) di plts 3000 watt klinik layanan kesehatan cumacuma dompet duaffa Palembang.

\section{METODE PENELITIAN}

\subsection{Diagram Fishbone Penelitian}

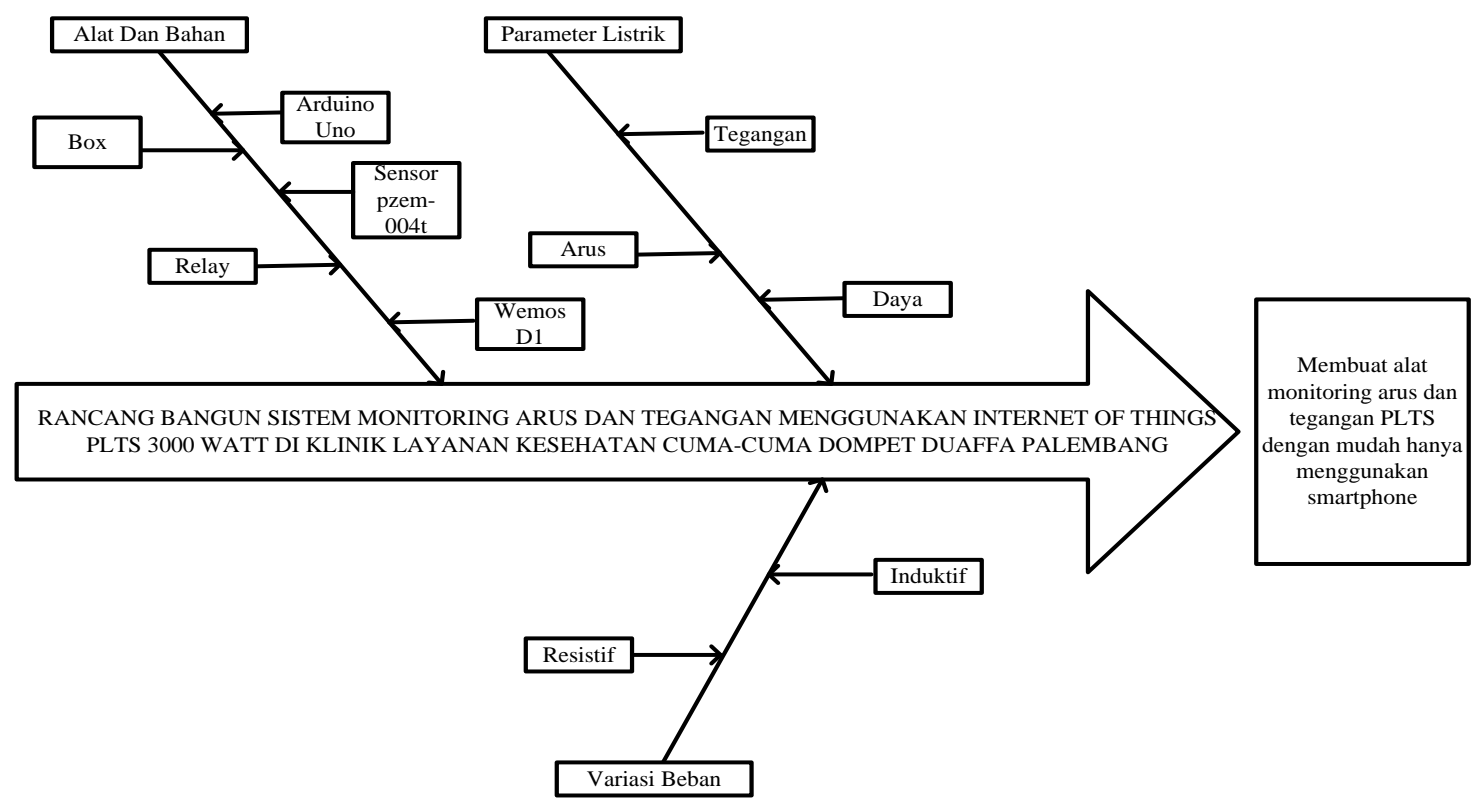

Gambar 1. Diagram Fishbone

\subsection{Alat dan Bahan}

Adapun beberapa peralatan yang diperlukan dalam penelitian ini adalah sebagai berikut:

1. Arduino Uno

2. Wemos D1

3. Sensor Pzem004t 

4. Relay
5. Solder
6. Box
7. Lem Tembak
8. Kabel Jamper
9. Kabel
10.Stop kontak
11.Steker

\subsection{Perancangan Software}

Perancangan ini meliputi pembuatan program pada arduino uno dan wemos D1 yang akan dijalankan pada arduino IDE. Arduino IDE merupakan software editor yang memungkinkan kita menuliskan bahasa pemograman dengan alur algoritma yang disusun berdasarkan flowchart yang sudah disusun. Tedapat beberapa bagian script yang difungsikan pada perancangan ini meliputi Inisialisasi Pin dan Variabel, Inisialisasi I/O, Modulasi sinyal PWM, Pensaklaran Pin PWM, dan Pengolahan Data Feedback.[6], [7],[8]. Berikut ini adalah script pemrograman yang digunakan:

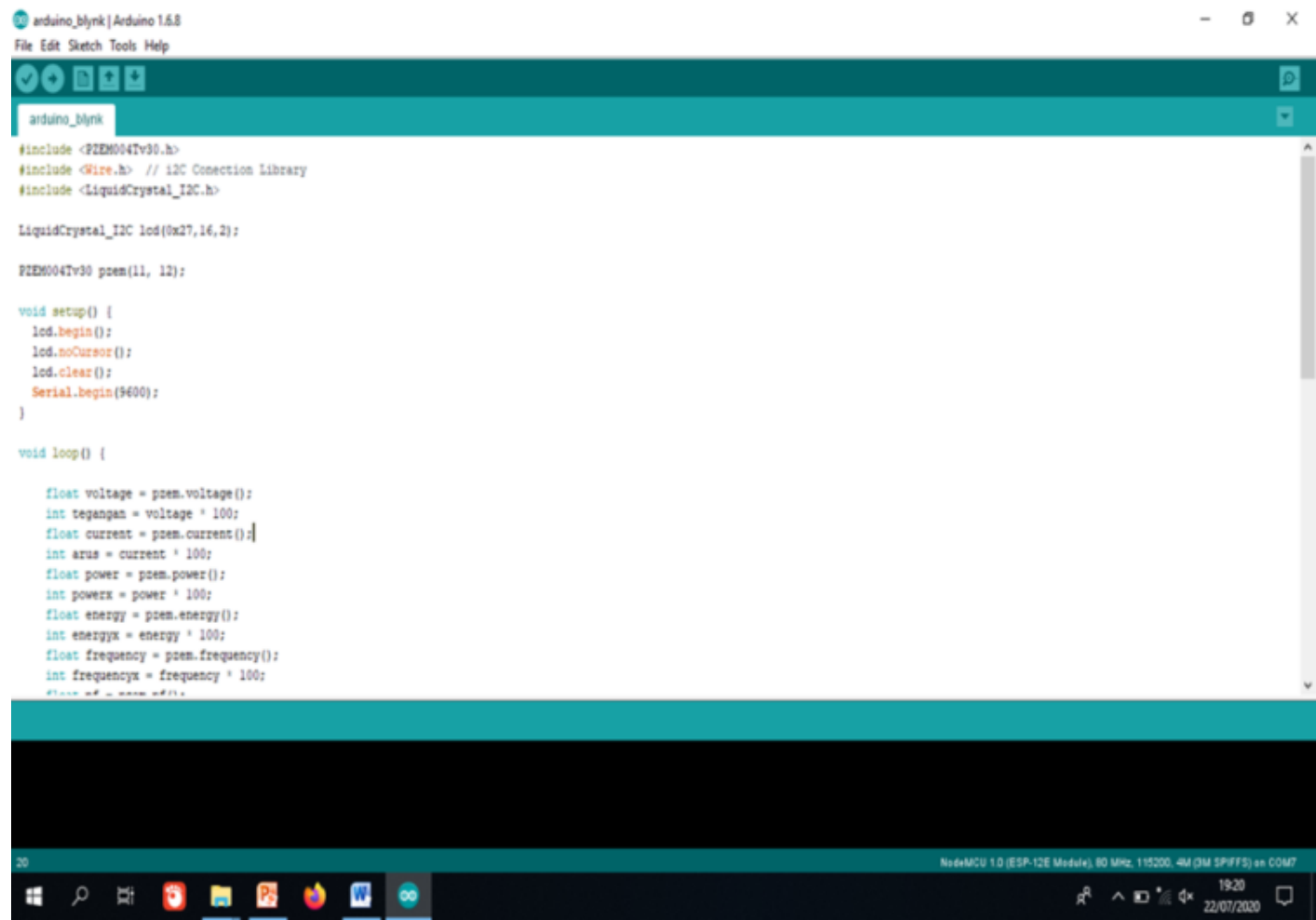

Gambar 2. Pembuatan Program pada Arduino IDE

\subsection{Perancangan Perangkat Keras}

Sistem Perancangan perangkat keras sistem. Dimana controller yang digunakan disini adalah arduino uno dan wemos D1, digunakan controller wemos yang memiliki dukungan konektivitas Wi-Fi. Untuk pemrosesan data yang didapat oleh sensor digunakan blynk dengan sistem operasi blynk. Untuk memproses data sensor pzem004t akan mengirimkan data kearduino uno lalu diteruskan ke wemos d1 dan data dari wemos d1 akan tampil pada aplikasi blynk lalu data arus dan tegangan yang terpakai akan tampil di aplikasi blynk.[9], [10]. 


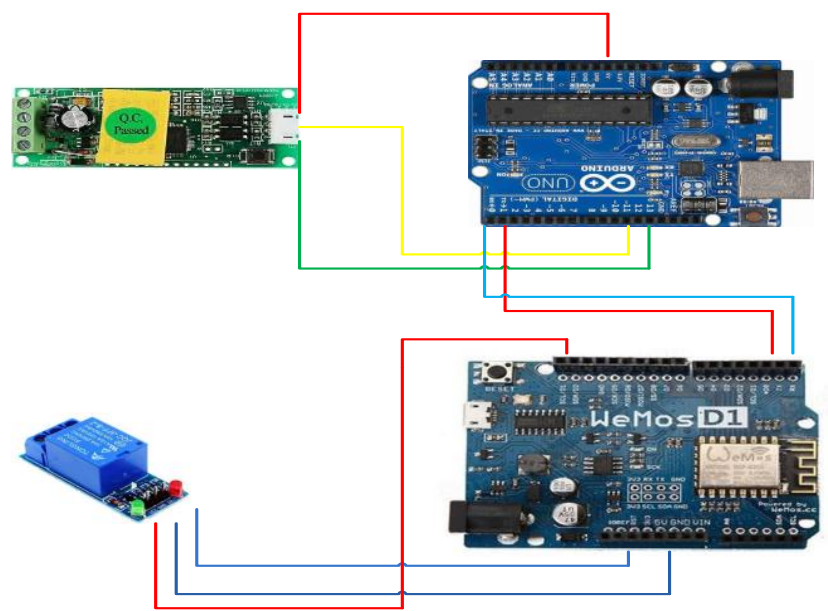

Gambar 3. Diagram Perancangan Alat

\section{HASIL DAN PEMBAHASAN}

\subsection{Hasil Perancangan}

Hasil rancang bangun sistem monitoring output dan pencatatan data pada panel surya berbasis mikrokontroler Arduino dapat dilihat pada Gambar 4

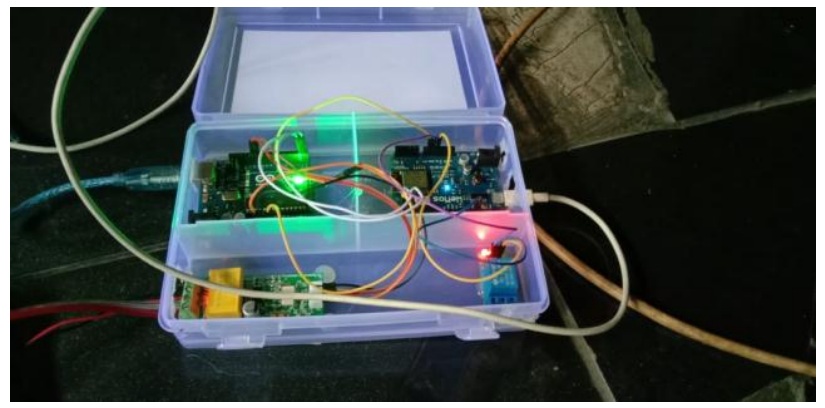

Gambar 4. Hasil Rancang Bangun Sistem Monitoring Arus dan Tegangan

\section{2 Data Pengukuran PLTS Variasi Beban Induktif}

Tabel 1. Data Hasil Pengukuran Variasi Beban Induktif

\begin{tabular}{|c|c|c|c|c|}
\hline \multicolumn{5}{|c|}{ Tabel Beban Induktif $500 \mathrm{~W}$} \\
\hline Waktu & Vin & Iin & Vout & Iou \\
\hline $8: 00$ & 13 & 34,6 & 227 & 0,186 \\
$9: 00$ & 13 & 34,6 & 227 & 0,186 \\
$10: 00$ & 13 & 33,1 & 227 & 0,182 \\
$11: 00$ & 13 & 32 & 227.8 & 0,180 \\
$12: 00$ & 13 & 27,7 & 227.8 & 0,165 \\
$13: 00$ & 13 & 30 & 227.8 & 0,174 \\
$14: 00$ & 13 & 32 & 227.8 & 0,180 \\
$15: 00$ & 13 & 33,1 & 227.8 & 0,182 \\
\hline
\end{tabular}

Aldiansyah, et., al [Monitoring Arus dan Tegangan Pembangkit Listrik Tenaga Surya Menggunakan Internet of Things] 


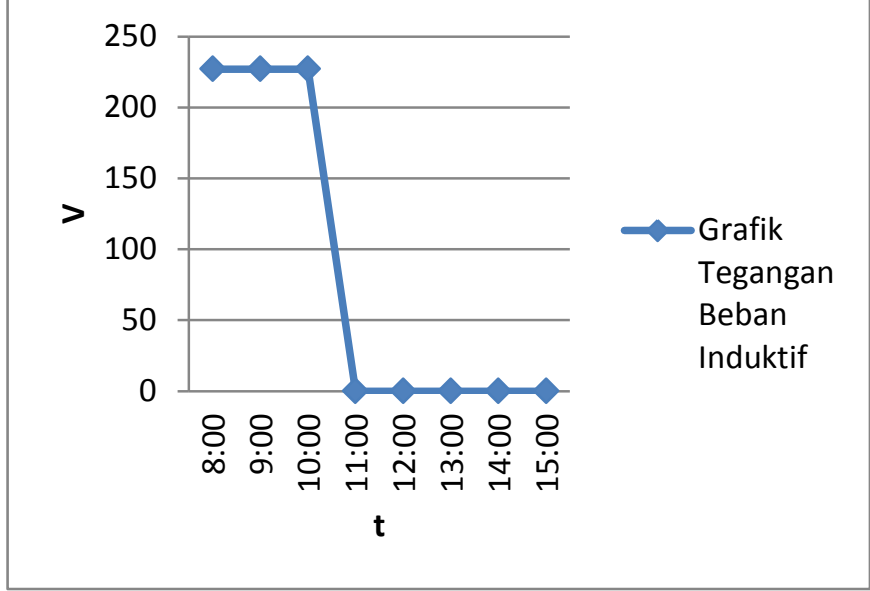

Gambar 5. Grafik Tegangan Beban Induktif

Pada grafik diatas menjelaskan tegangan yang mengalir menuju beban, dimana terlihat pada pukul 08.00- 10.00 tegangan terlihat stabil pada nilai $227 \mathrm{~V}$, sedangkan pada pukul $11.00-$ 15.00 tegangan bergerak naik menjadi 227,8 .

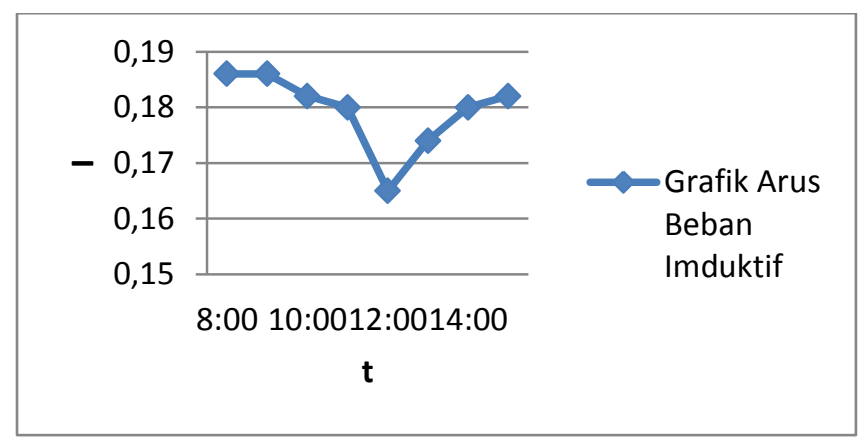

Gambar 6. Grafik Arus Beban Induktif

Pada gambar grafik diatas memperlihatkan arus beban induktif, dimana pada pukul 8.00 09.00 arus mengalir stabil di 0,186 , dan pada pukul $09.00-12.00$ arus yang mengalir terus berkurang, sedangkan pada pukul 13.00 - 15.00 arus yang mengalir mengalami peningkatan.

\subsection{Data Pengukuran PLTS Variasi Beban Resistif}

Tabel 2. Data Hasil Pengukuran Variasi Beban Resistif

\begin{tabular}{|c|c|c|c|c|}
\hline \multicolumn{5}{|c|}{ Data beban resistif 550 W } \\
\hline Waktu & Vin & Iin & Vout & Iout \\
\hline $8: 00$ & 13 & 42 & 227 & 0,186 \\
$9: 00$ & 13 & 39 & 227.8 & 0,180 \\
$10: 00$ & 13 & 38 & 227.8 & 0,176 \\
$11: 00$ & 13 & 36 & 227.8 & 0,170 \\
$12: 00$ & 13 & 34,6 & 227.8 & 0,168 \\
$13: 00$ & 13 & 34,6 & 227.8 & 0,168 \\
$14: 00$ & 13 & 34,6 & 227.8 & 0,168 \\
$15: 00$ & 13 & 34,6 & 227.8 & 0,168 \\
\hline
\end{tabular}




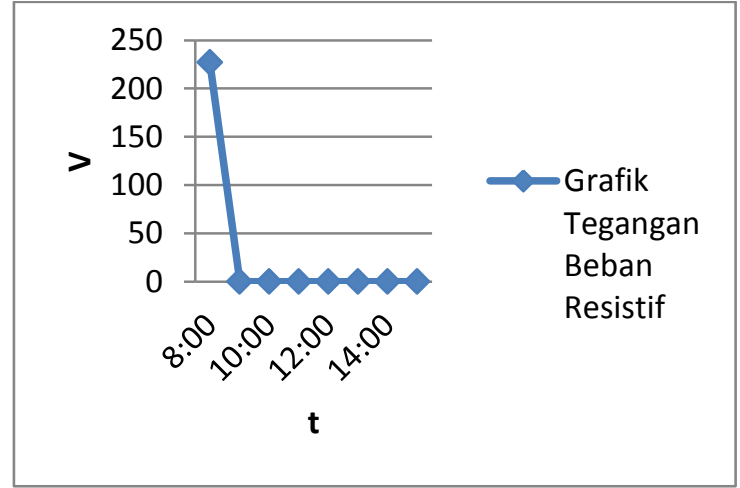

Gambar 7. Grafik Tegangan Beban Resistif

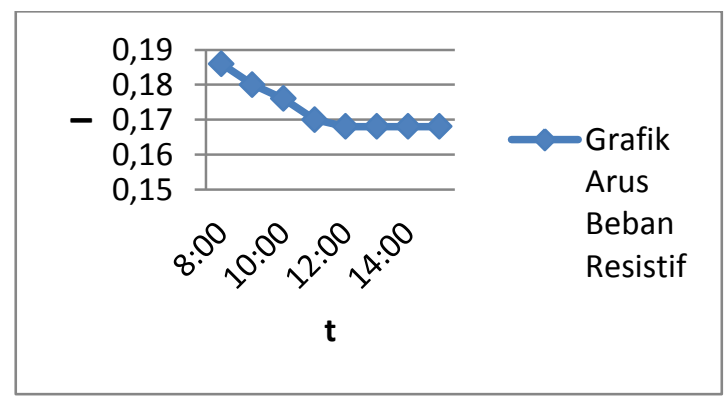

Gambar 8. Grafik Arus Beban Resistif

3.4 Hasil Percobaan Aplikasi Blynk

Hasil percobaan dari aplikasi blynk sistem monitoring arus dan tegangan data pada PLTS berbasis mikrokontroler Arduino dapat dilihat pada Gambar 4.8.

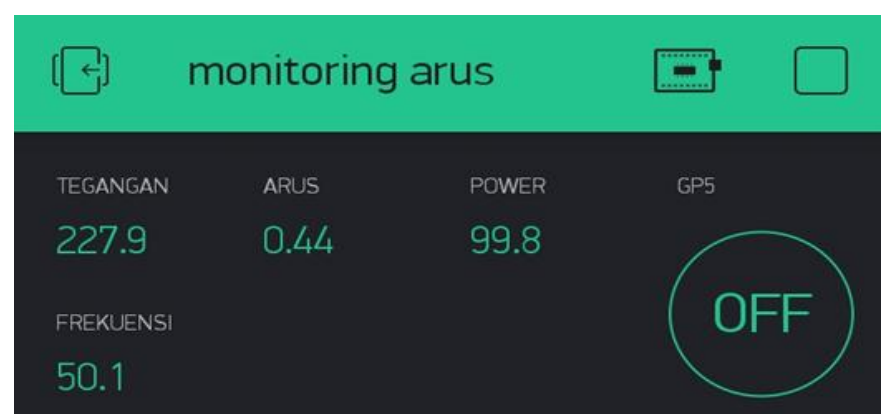

Gambar 9. Hasil Percobaan di Aplikasi blynk

\section{KESIMPULAN}

Dari hasil penelitian yang telah dilakukan dapat ditarik kesimpulan bahwa rancang bangun alat monitoring arus dan tegangan yang telah dibuat bekerja secara stabil dan optimal pada PLTS 3000 Watt dan bekerja dengan efisien karena bisa memonitoring arus dan tegangan secara real time menggunakan mikrokontroler Arduino. 


\section{SARAN}

Untuk penelitian selanjutnya disarankan untuk bisa melanjutkan penelitian dengan menambahkan fitur yang tidak hanya memonitoring bukan hanya monitoring arus dan tegangan saja tetapi alat tersebut juga bisa mengatasi gangguan pada beban.

\section{DAFTAR PUSTAKA}

[1] R. N. Hidayah. 2017, "Strategi Dompet Dhuafa Sumatera Selatan Dalam Menarik Minat Donatur Untuk Menyalurkan Dana Zakat Infak Sadaqah Wakaf (ZISWAF)," Intelektualita, Vol. 6, No. 1, p. 135.

[2] D. I. Layanan, K. C. Lkc, and D. Duafa. 2019, "Sosialisasi Penggunaan Inverter Berbasis Solar SeL, ”Vol. 3, No. 2, pp. 125-131.

[3] F. Habibi, S. Setiawidayat, and M. Mukhsim. 2017, "Alat Monitoring Pemakaian Energi Listrik Berbasis Android Menggunakan Modul PZEM-004T,” Pros. Semin. Nas. Teknol. Elektro Terap. Vol. 01, No. 01, pp. 157-162,.

[4] R. A. Dalimunthe. 2018, "Pemantau Arus Listrik Berbasis Alarm Dengan Sensor Arus Menggunakan Mikrokontroller Arduino Uno," Semin. Nas. R. 2018, Vol. 9986, No. September, pp. 333-338.

[5] Y. Efendi, 2018, "Internet of Things (Iot) Sistem Pengendalian Lampu Menggunakan Raspberry Pi Berbasis Mobile," J. Ilm. Ilmu Komput., Vol. 4, No. 2, pp. 21-27.

[6] J. Arifin, L. N. Zulita, and Hermawansyah. 2016, "Perancangan Murottal Otomatis Menggunakan Mikrokontroller Arduino Mega 2560,” J. Media Infotama, Vol. 12, No. 1, pp. 89-98.

[7] N. Arifin, R. S. Lubis, and M. Gapy. 2019, "Rancang Bangun Prototype Power Meter 1 Fasa," Vol. 4, No. 1, pp. 13-22.

[8] M. A. Alipudin and et. al. 2019, "Rancang Bangun Alat Monitoring Biaya Listrik Terpakai Berbasis Internet of Things (Iot)," pp. 1-11.

[9] Bahrin. 2017, "Sistem Kontrol Penerangan Menggunakan Arduino Uno pada Universitas Ichsan Gorontalo," Ilk. J. Ilm., Vol. 9, pp. 282-289,

[10] R. Biasrori, I. W. A. Arimbawa, and I. W. Wedashwara W. 2019, "Sistem Pendukung Keputusan Konsumsi Listrik Dengan Implementasi Iot dan Fuzzy Rule Mining,” J. Inform. dan Rekayasa Elektron., Vol. 2, No. 1, p. 60. 